\title{
Sistem Informasi Penjualan Distro Monkey School Store Berbasis Android
}

\author{
Paryanta $^{* 1}$, Ratna Herawati ${ }^{2}$, Riyan Renaldhi ${ }^{3}$ \\ ${ }^{1}$ Program Studi Teknik Komputer, STMIK AUB, Surakarta, Indonesia \\ ${ }^{2,3}$ Program Studi Sistem Informasi, STMIK AUB, Surakarta, Indonesia \\ e-mail: *1paryanta@stmik-aub.ac.id, ${ }^{2}$ ratna.herawati@stmik-aub.ac.id, \\ ${ }^{3}$ logamradikal@gmail.com
}

\begin{abstract}
Abstrak
Monkey School Store adalah sebuah distro (distribution store) yang berada di Sragen. Distro tersebut menyediakan beraneka macam pakaian bertema musik. Seiring bertambahnya pelanggan, sistem berbelanja yang dimana pelanggan harus datang ke distro, menimbulkan kesulitan bagi pelanggan yang lokasinyajauh.

Tujuan penelitian ini adalah membangun aplikasi penjualan berbasis android sebagai media informasi, penjualan bagi distro Monkey School Store dan memudahkan pelanggan dalam melakukakan transaksi pemesanan barang. Dalam membangun sistem ter sebut metode yang digunakan adalah metode perancangan dengan menggunakan metode waterfall. Metode pengumpulan data dengan metode observasi, metode wawancara dan studi pustaka. Sebagai alat bantu analisis dan perancangan yang digunakan adalah flowchart, DFD (Data Flow Diagram), dan Entity Relationship Diagram. Sedangkan bahasa pemograman pendukungyang digunakan adalah Apache Cordova, PHP, Java, dan MySQL sebagai database.

Hasil dari penelitian ini adalah membuat suatu aplikasi sistem informa si penjualan distro berbasis Android yang dapat memudahkan pelanggan untuk melakukan pemesanan produk maupun pemilik distro untuk memasarkan produknya.
\end{abstract}

Kata kunci-Android, Penjualan, Pakaian, Distro, DFD

\section{Abstract}

Monkey School Store is a distro (distribution store) in Sragen. The distro provides a wide variety of music themed clothing. As customers increase, the shopping system where customers have to come to the distro, creates difficulties for customers who are far away.

The purpose of this research is to build Android-based sales application as an information media, sales for Monkey School Store distro and make it easier for customers to carry out goods order transactions. In building the system approach method used is desing method by using waterfall method. Methods of data collection by observation method, interview method, and study of literature. As a tool of analysis and design used is flowchart, DFD (Data Flow Diagram), and Entity Relationship Diagram. While the supporting programming languages used are Apache Cordova, PHP, Java, and MySQL as the database.

The result of this research is to make an Android-based distro sales information system application that can make it easier for customers to order product and distro owner to market their products.

Keywords- Android, Sales, Clothing, Distro, DFD 


\section{PENDAHULUAN}

Perkembangan teknologi informasi mengalami kemajuan dan perkembangan yang cukup pesat dalam kehidupan manusia. Kemajuan teknologi informasi yang pesat salah satunya adalah android. Android menyediakan platform yang lengkap, terbuka, dan bebas sehingga memberikan programmer untuk melakukan pengembangan sesuai dengan yang diharapkan. Ditambah dengan adanya internet yang dapat menyampaikan informasi secara cepat dan luas. Internet merupakan tempat terhubungnya berbagai mesin komputer yang mengolah informasi di dunia, dengan internet kita bisa mendapat jutaan informasi, mulai dari teknologi, budaya, pemerintahan, musik, berita koran dari seluruh dunia, bahkan kita dapat berbisnis melalui internet. Perkembangan yang pesat pun ditunjukkan di bidang fashion. Bagi fashionista (sebutan untuk pecinta fashion), fashion adalah sebuah gaya hidup yang tidak bisa lepas dari keseharian.

Penampilan merupakan suatu hal yang sangat penting untuk menunjang rasa kepercayaan diri dan berbagai hal. Membeli sebuah barang dengan brand yang sedang terkenal atau update adalah sebuah hobi dan dapat memberikan kepuasan tersendiri. Salah satu pihak yang diuntungkan tentunya adalah pengusaha Distribution Store (Distro) yang ada guna memenuhi kebutuhan fashion masyarakat. Distro Monkey School Store merupakan sebuah distro yang berada di daerah Sragen.

Distro tersebut menyediakan beraneka macam pakaian khususnya pakaian bertema Musik. Seiring dengan bertambahnya pelanggan Distro Monkey School Store, sistem berbelanja yang dimana pelanggan harus datang ke distro, menimbulkan kesulitan bagi pelanggan yang lokasinya berjauhan dengan Distro Monkey School Store. Maka dari itu, perlu adanya inovasi untuk menangani masalah ini serta dapat menyedot animo dari para fashionista tersebut. Sekarang ini banyak dijumpai website maupun akun di media sosial yang dibuat khusus untuk memasarkan dan menjual produk atau brand yang akan ditawarkan yang biasa disebut dengan E-commerce. Namun, disaat sekarang yang segala serba mobile tentu ide mobile commerce tidaklah begitu buruk. Sehingga merupakan langkah yang tepat apabila selanjutnya banyak para pengusaha khususnya dibidang fashion yang kemudian mencoba untuk memberdayakan telepon seluler sebagai media transaksi yang baru.

Berdasarkan gambaran di atas, maka peneliti bermaksud mengabungkan perkembangan teknologi serta fashion dengan merancang dan membangun sebuah aplikasi mobile berbasis Android sebagai media informasi dan pejualan online pada distro yang dituangkan dalam bentuk skripsi berjudul "Sistem Informasi Penjualan Distro Monkey School Store berbasis Android".

\section{METODE PENELITIAN}

Dalam pembuatan Aplikasi Sistem Informasi Penjualan Distro Monkey School Store Berbasis Android ini penulis menggunakan metode pengembangan sistem dengan metode Waterfall. Metode ini dipilih oleh penulis karena metode Waterfall mempunyai tahapan sistem yang terstruktur sehingga sesuai dalam ruang lingkup penelitian dan pengembangan sistem dengan metode Waterfall. Metode Waterfall adalah suatu proses pengembangan perangkat lunak berurutan, di mana kemajuan dipandang sebagai terus mengalir ke bawah (seperti air terjun) melewati fase-fase perencanaan, pemodelan, konstruksi, pengujian dan implementasi. Berikut adalah fase-fase pengembangan perangkat lunak berurutan / linear yang dapat dilihat pada Gambar 1 (Pressman, 2001). 


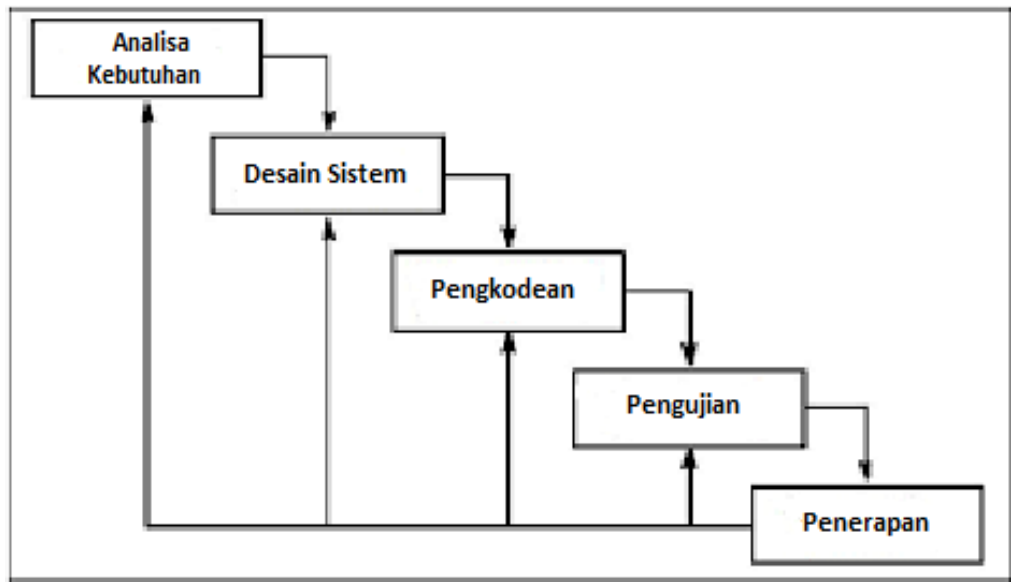

Gambar 1 Siklus Metode Waterfall

\subsection{Analisa sistem}

Untuk menganalisa kelemahan sistem diperlukan langkah untuk mengidentifikasi dan memberikan solusi terhadap kelemahan sistem yang ada, maka sebagai landasan penulis menggunakan metode atau kerangka PIECES yang terdiri dari performance, information, economy, control, efficiency dan service. Analisis ini digunakan sebagai alat ukur untuk menentukan sistem baru layak atau tidak karena enam aspek ini harus mengalami peningkatan ukuran yang lebih baik dari sistem lama agar dapat mendukung dalam kelancaran proses admin. Analisa kelemahan sistem seperti pada Tabel 1.

Tabel 1 Analisa Kelemahan Sistem

\begin{tabular}{|l|l|}
\hline \multicolumn{1}{|c|}{ Analisa } & \multicolumn{1}{c|}{ Sistem yang sedang berjalan } \\
\hline $\begin{array}{l}\text { Perfomance } \\
\text { (Kinerja) }\end{array}$ & $\begin{array}{l}\text { Pengolahan data masih dilakukan secara manual. Belum menggunakan } \\
\text { sistem apapun. }\end{array}$ \\
\hline $\begin{array}{l}\text { Information } \\
\text { (Informasi) }\end{array}$ & $\begin{array}{l}\text { Informasi yang disampaikan kurang detail. Karena harus menunggu } \\
\text { pelanggan menghubungi pemilik distro guna menanyakan ketersediaan } \\
\text { barang, ukuran, dan harga. }\end{array}$ \\
\hline $\begin{array}{l}\text { Economy } \\
\text { (Ekonomi) }\end{array}$ & Pemasukan kurang karena cakupan wilayah yang terbilang sempit. \\
\hline $\begin{array}{l}\text { Control } \\
\text { (Keamanan) }\end{array}$ & $\begin{array}{l}\text { Keamanan data lemah, karena laporan penjualan, dan } \text { stock barang } \\
\text { dicatat dalam sebuah buku sehingga rentan rusak dan hilang. }\end{array}$ \\
\hline $\begin{array}{l}\text { Efficiency } \\
\text { (Efisiensi) }\end{array}$ & $\begin{array}{l}\text { Pelanggan masih harus bertanya kepada pemilik distro karena tidak ada } \\
\text { katalog barang. }\end{array}$ \\
\hline $\begin{array}{l}\text { Service } \\
\text { (Layanan) }\end{array}$ & $\begin{array}{l}\text { Pelayanan kurang karena keterbatasan karyawan untuk menjelaskan } \\
\text { info produk bagi pelanggan yang datang ke toko. }\end{array}$ \\
\hline
\end{tabular}

\subsection{Diagram konteks}

Pada Aplikasi Monkey Store dibuatkan diagram konteks agar pengguna dapat mengerti alur dalam program, berikut diagram konteks Aplikasi Monkey Store seperti pada Gambar 2. 


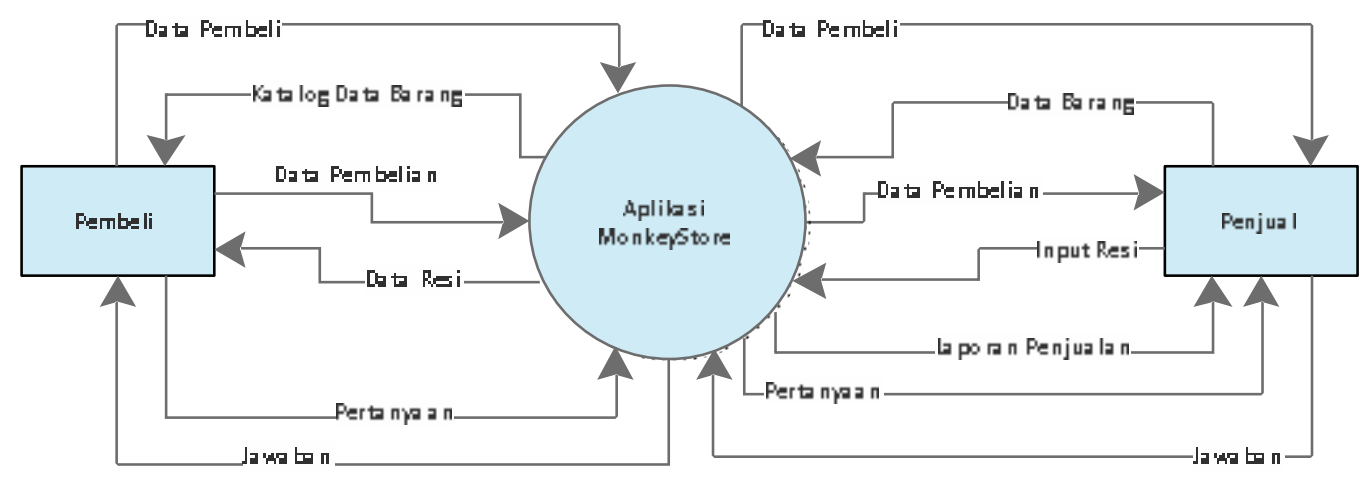

Gambar 2 Diagram Konteks Aplikasi Monkey Store

Gambar 2 merupakan Diagram Konteks Aplikasi Monkey Store, pembeli akan memasukan data pembeli kedalam aplikasi sehingga penjual akan dapat memantau data pembeli yang terdaftar. Lalu penjual akan memasukan data barang yang nantinya akan ditampilkan berupa katalog barang dalam aplikasi kepada pembeli. Pembeli akan memasukan data pembelian ke dalam aplikasi lalu penjual akan memasukan nomor resi pengiriman kepada pembeli. Pada saat proses diatas juga terdapat proses tanya jawab antara pembeli dan penjual yang memanfaatkan fitur kotak masuk aplikasi.

\section{HASIL DAN PEMBAHASAN}

\subsection{Tampilan halaman login user}

\section{MonkeySchool \\ Distro}

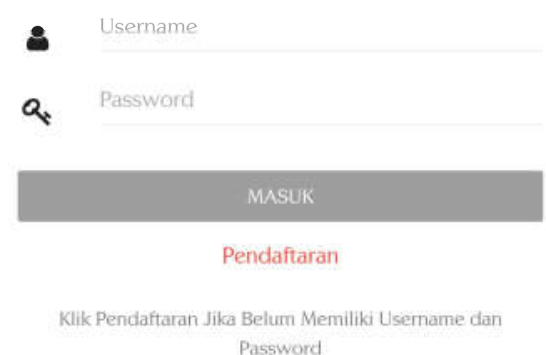

Gambar 3 Tampilan halaman login user

Keterangan Gambar 3 Halaman login user, menampilkan form yang berisi username dan password untuk digunakan pembeli untuk masuk ke halaman menu utama pada aplikasi. 


\subsection{Tampilan Halaman Pendaftaran}

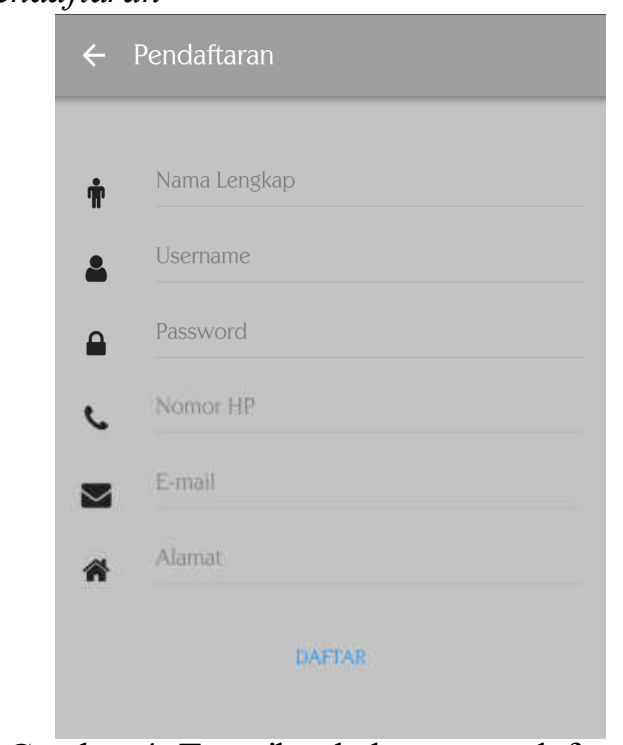

Gambar 4 Tampilan halaman pendaftaran

Keterangan Gambar 4 Halaman pendaftaran digunakan untuk mendaftar ke aplikasi, seluruh form pendaftaran harus di isi sebelum menekan tombol dafar. Username dan password yang didaftarkan digunakan unuk masuk ke aplikasi.

\subsection{Tampilan halaman menu utama}

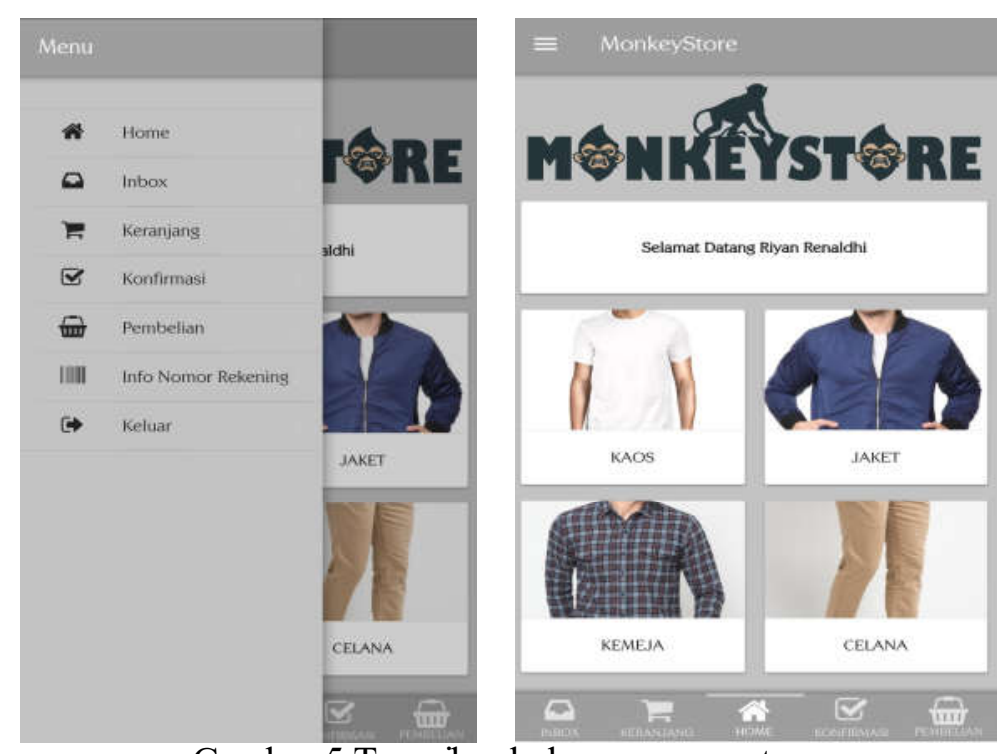

Gambar 5 Tampilan halaman menu utama

Keterangan Gambar 5 Halaman menu utama, menampilkan daftar kategori barang dan terdapat juga menu utama aplikasi yaitu home, inbox, keranjang, konfirmasi dan pembelian. Untuk daftar kategori barang digunakan untuk menampilkan daftar barang sesuai kategori yang dipilih.

\subsection{Tampilan Halaman daftar barang}

GO INFOTECH: JURNAL ILMIAH STMIKAUB Vol. 26, No. 2, Desember 2020: 164-173 


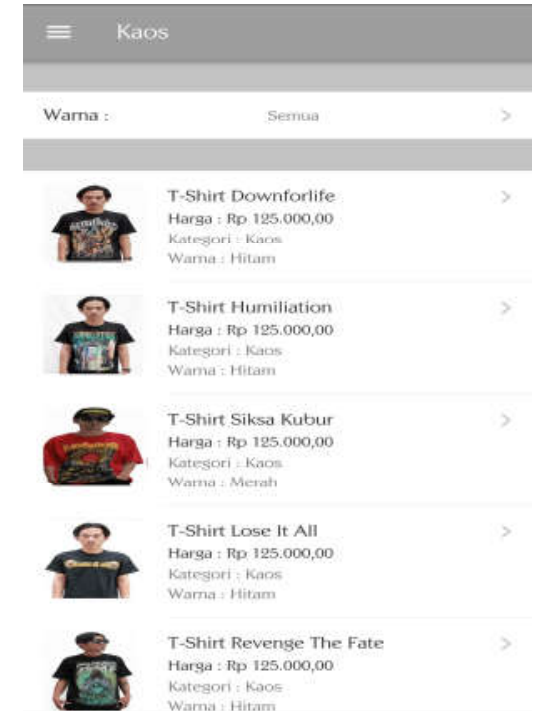

Gambar 6 Tampilan halaman daftar barang

Keterangan Gambar 6 Halaman tampilan daftar barang akan muncul setelah memilih salah satu dari kategori di menu utama. Pada halaman tampilan daftar barang ini menampilkan daftar barang berdasarkan kategori yang dipilih dan juga terdapat filter berdasarkan warna yang dipilih.

\subsection{Tampilan halaman detail barang}

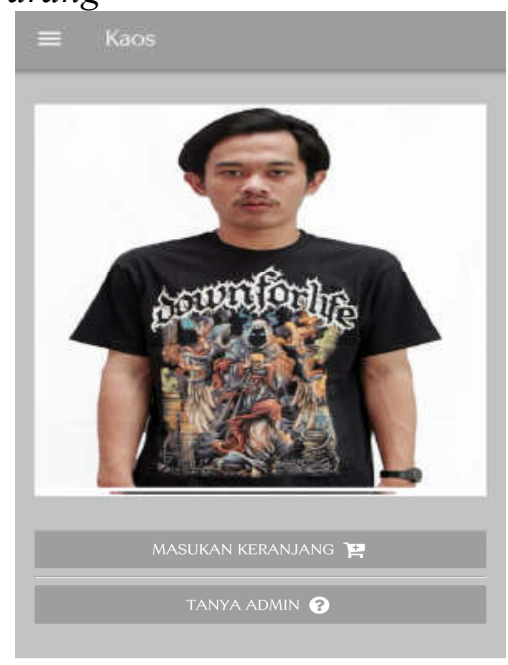

T-Shirt Downforlife

$$
\begin{array}{ll}
\text { Kode Barans } & \text { : TS0001 } \\
\text { Harsa } & \text { : Rn. } 125000
\end{array}
$$

Gambar 7 Tampilan halaman detail barang

Keterangan Gambar 7 Halaman detail barang menampilkan informasi mengenai seluruh detail barang. Pada halaman ini pembeli bisa langsung menanyakan mengenai detail barang dengan cara klik tombol Tanya ke admin. Apabila pembeli merasa cocok pembeli tinggal menekan tombol masukan keranjang untuk memasukan barang ke keranjang.

\subsection{Tampilan halaman kotak masuk}




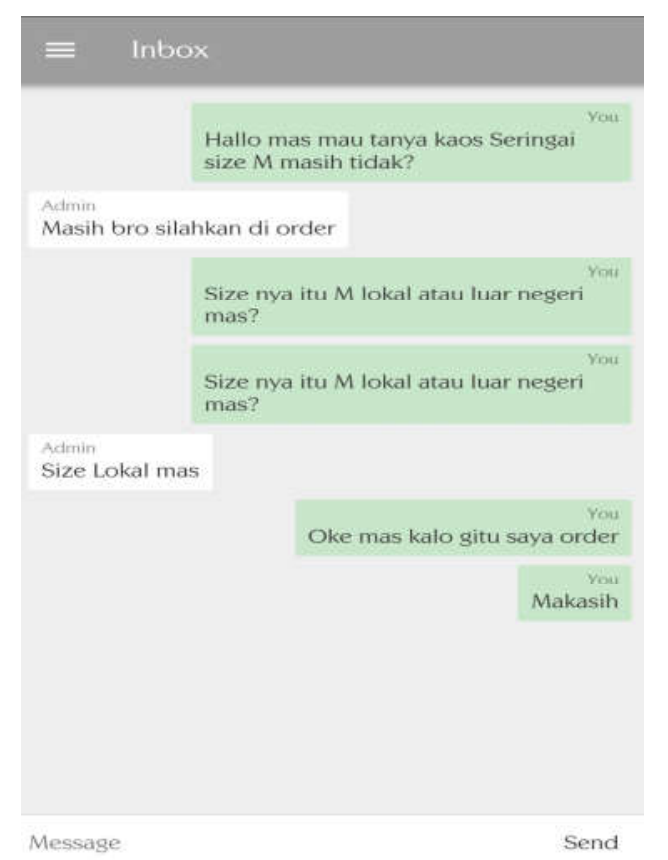

Gambar 8 Tampilan halaman kotak masuk

Keterangan Gambar 8 Tampilan halaman kotak masuk dapat diakses melalui menu inbox pada menu utama, halaman ini digunakan untuk berkomunikasi langsung antara pembeli dan penjual. Pembeli dapat mengirimkan pertanyaan melalui kotak masuk ini. Balasan oleh admin atau penjual akan muncul di halaman kotak masuk ini juga.

\subsection{Tampilan halaman keranjang}

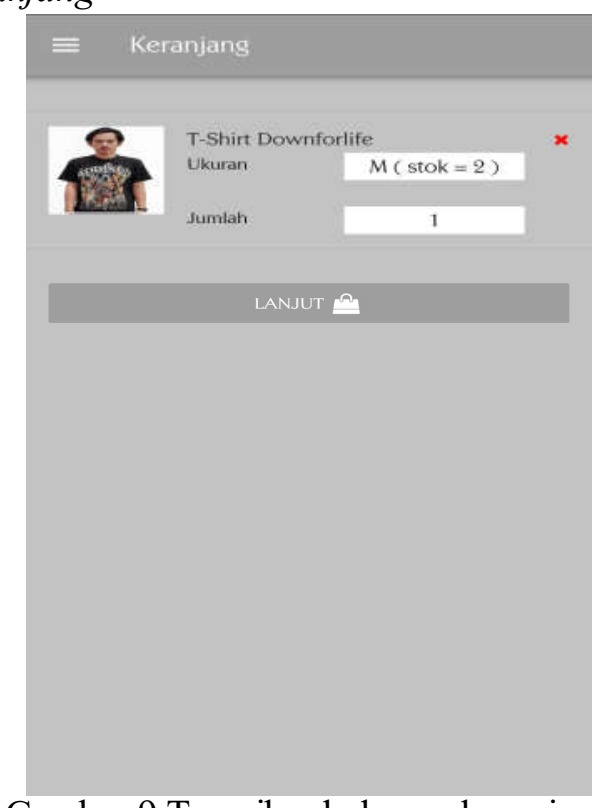

Gambar 9 Tampilan halaman keranjang

Keterangan Gambar 9 Tampilan Halaman keranjang dapat diakses melalui menu keranjang pada menu utama, halaman ini menampilkan daftar barang yang sudah dipilih dan dimasukan ke dalam keranjang. Pada halaman ini pembeli akan memilih ukuran dan memasukan jumlah barang yang ingin dibeli. Setelah memasukan ukuran dan jumlah barang yang ingin dibeli. Tombol lanjut digunakan untuk melanjutkan proses pembelian.

\subsection{Tampilan halaman checkout}

GO INFOTECH: JURNAL ILMIAH STMIKAUB Vol. 26, No. 2, Desember 2020: 164-173 


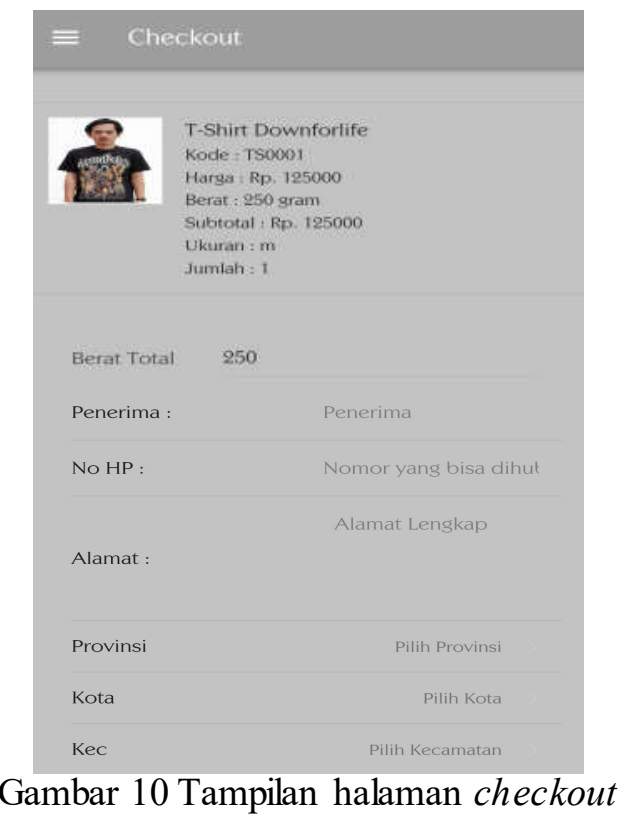

Keterangan Gambar 10 Tampilan halaman checkout, menampilkan daftar barang yang akan dibeli dan terdapat inputan mengenai informasi alamat pengiriman dan ekspedisi jasa pengiriman yang akan digunakan.

\subsection{Tampilan halaman daftar konfirmasi pembayaran}

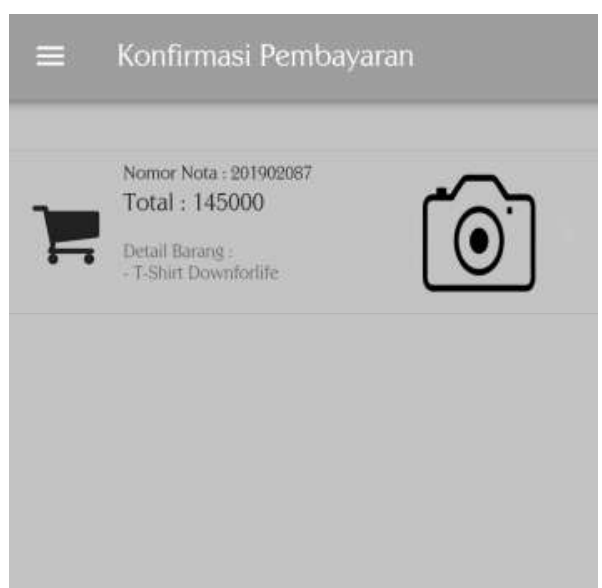

Gambar 11 Tampilan halaman daftar konfirmasi pembayaran

Keterangan Gambar 11 Tampilan halaman daftar konfirmasi dapat diakses melalui menu konfirmasi pada menu utama, halaman ini menampilkan daftar pembelian yang belum dilakukan konfirmasi pembayaran. Konfirmasi pembayaran dilakukan dengan cara mengupload foto bukti transfer yang nantinya akan diverifikasi oleh penjual.

\subsection{Tampilan halaman daftar pembelian}




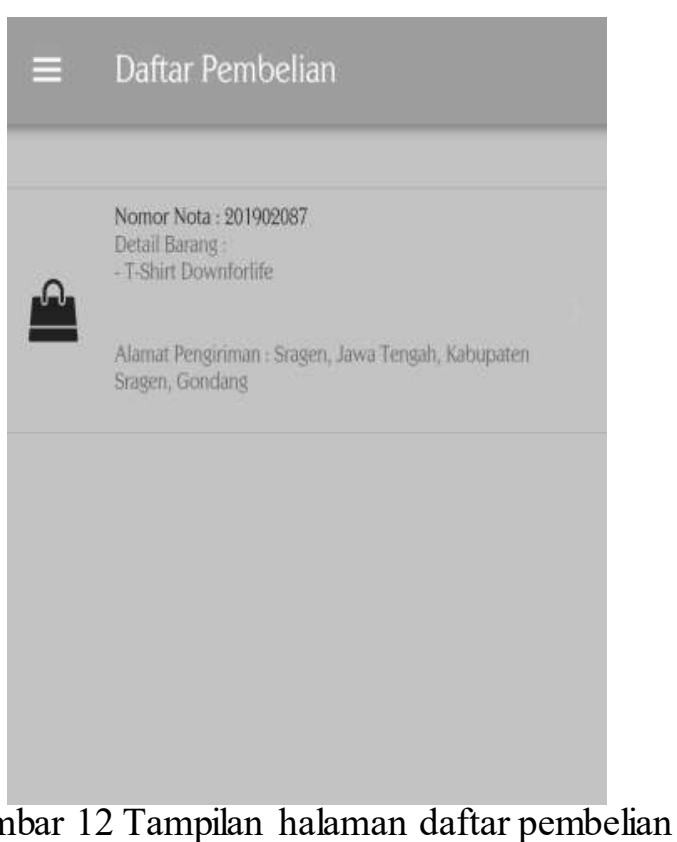

Keterangan Gambar 12 Tampilan halaman daftar pembelian dapat diakses melalui menu pembelian pada menu utama. Halaman ini menampilkan daftar pembelian yang sudah dikonfirmasi pembayaran oleh pembeli dan sudah diverifikasi oleh penjual. Apabila barang sudah dikirim ke jasa ekspedisi pengiriman, maka penjual akan menginput nomor resi pengiriman dan pembeli dapat memantaunya dari halaman ini.

\section{KESIMPULAN}

Hasil perancangan Sistem Informasi Penjualan Distro Monkey Schol Store Berbasis Android, diambil kesimpulan bahwa :

1. Sistem yang dibangun dapat membantu pelanggan untuk melihat katalog dari Distro Monkey School Store melalui aplikasi android dan melakukan transaksi pembelian barang tanpa harus datang ke toko, serta membantu memudahkan pemilik distro dalam memasarkan produk yang dijual.

2. Sistem informasi penjualan yang di usulkan telah memenuhi fungsi-fungsi yang diharapkan, seperti pengolahan data barang, penjualan barang, dan pembuatan laporan penjualan barang.

3. Metode pengumpulan data menggunakan metode observasi, wawancara, pustaka dan metode pengembangan sistem. Alur sistem menggunakan Flowchart, Data Flow Diagram, Data Flow Diagram Level 0, Data Flow Diagram Level 1, Context Diagram dan Tabel Relasi. Metode pengembangan sistem menggunakan metode Waterfall.

4. Pengembangan sistem menggunakan Bahasa pemrograman pendukung Cordova, PHP, Java dan MySQL sebagai pengolahan database. Sistem ini melakukan pengolahan data kategori, produk, form pemesanan, laporan penjualan.

\section{SARAN}

Saran yang penulis ajukan demi pengembangan aplikasi Sistem Informasi Penjualan Distro Monkey School Store agar menjadi lebih baik kedepannya adalah sebagai berikut:

1. Menambahkan fitur tracking barang sesuai nomor resi agar memudahkan pembeli dalam melacak sampai mana barang dikirim.

2. Diharapkan nantinya aplikasi android ini dikembangkan untuk melakukan pembayaran menggunakan uang virtual. 
3. Diharapkan memiliki menu retur/pengembalian barang.

\section{DAFTAR PUSTAKA}

[1] Al-Bahra bin Ladjamudin. 2005. Analisis dan Desain Sistem Informasi. Yogyakarta : Graha Ilmu.

[2] Andri Kristanto. 2003. Perancangan Sistem Infrmasi dan Aplikasinya. Gava Media. Jakarta.

[3] Aplikasi. (2018, Desember 25). Di Wikipedia, Ensiklopedia Bebas. Diakses pada 07:10, Desember 25, 2018, dari https://id.wikipedia.org/w/index.php?title=Aplikasi\&oldid $=14615286$

[4] Basu Swastha, Hani Handoko. 2011. Manajemen Pemasaran-Analisis Perilaku Konsumen. Yogyakarta :BPFE.

[5] DeCoster, J. 2012. Advances OpenJDK Project with New Code, NetBeans Integration Governance Board and Availability of Compatibility Tests.

[6] Distro (pakaian). (2016, Maret 20). Di Wikipedia, Ensiklopedia Bebas, Diakses pada 00:45, Maret 20, 2016, dari https://id.wikipedia.org/w/index.php?title=Distro (pakaian)\&oldid=11448786

[7] Haryanto, Toni. 2016. Membuat Aplikasi Android Berbasis HTML5 dengan Cordova. https://www.codepolitan.com/membuat-aplikasi-android-berbasis-html5-cordova

[8] Henry Simanora. 2000. Basis Pengambilan Keputusan Bisnis. Salemba Empat. Jakarta.

[9] Jogiyanto, H.M. 2005. Analisa dan Desain Sistem Informasi: Pendekatan Terstruktur Teori dan Praktik Aplikasi Bisnis. ANDI. Yogyakarta.

[10] Kurniawan, Ninuk. 2015. Aplikasi Pemesanan Dan Penjualan Cat Berbasis Android. Tugas Akhir: Politeknik NegeriBatam.

[11] Lase , Felisia. 2017. Perancangan Sistem Informasi Penjualan Pada Fel's Shop Berbasis Web Di Batam. Skripsi Thesis: STMIK Gici Batam.

[12] M. Suyanto. 2004. Aplikasi Desain Grafis Untuk Periklanan. Yogyakarta :Andi.

[13] Marjito. 2016. Aplikasi Penjualan Online Berbasis Android Toko Hoax Merch. Bandung: STMIK Mardira Indonesia.

[14] Nazruddin Safaat H. 2012 (Edisi Revisi). Pemrograman Aplikasi Mobile Smartphone dan Tablet PC Berbasis Android. Informatika. Bandung.

[15] O'Brien, James A. dan George M.Marakas. 2010. Management Information System, $8^{\text {th }}$ $E d$. New York. McGraw-Hill-Irwin. New York.

[16] Pressman, Roger, S. 2001. Software Engineering: Apractitioner's Approach, Fifth Ed. New York. McGraw-Hill Book Company.

[17] Ronald G.Askin and Jeffrey B. Goldberg. 2001. Design and Analysis of Lean Production Systems.

[18] Sandi, Mulyana. 2014. Bikin Website dengan Aplikasi-aplikasi Gratis, Cepat, Mudah, dan Murah. MediaKom : Yogyakarta.

[19] Stzinger, Jackson, Burd. 2010. "System Analisis and Design With the Unified Process". USA: Course Technology. Cengage Learning.

[20] Sukamto, Rosa A. dan M. Salahuddin. 2014. Rekayasa Perangkat Lunak Terstruktur dan Berorientasi Objek. Bandung: Informatika.

[21] Williams, B.K, \& Sawyer, S. C. 2007. Using Information Technology: Pengenalan Praktis Dunia Komputer dan Komunikasi (edisi 7) (Penerjemah: Nur Wijayaning Rahayu \& Th. Arie Prabawati), Andi, Yogyakarta. 